\title{
Определение подлинности масла какао по данным ВЭЖХ о триглицеридном составе
}

\author{
(C) 2020 Рудаков О.Б. ${ }^{1}$, Рудакова Л.В. ${ }^{2}$, Саранов И.А. ${ }^{3}$, \\ Букша M.С. ${ }^{2}$, Рудаков Я.О. ${ }^{1}$ \\ ${ }^{1}$ Воронежский государственный технический университет, Воронеж \\ ${ }^{2}$ Воронежский государственный медицинский университет им. Н.Н. Бурденко, Воронеж \\ ${ }^{3}$ Воронежский государственный университет инженерных технологий, Воронеж
}

Поступила в редакцию 27.05.2020 г.

DOI: $10.17308 /$ sorpchrom.2020.20/2876

Масло какао (МК) является дорогим сырьевым компонентом шоколада, формирующим отличительные органолептические свойства шоколадной кондитерской продукции. Существует также широкая линейка эквивалентов масла какао, заменителей и улучшителей, которые по теплофизическим свойствам - температурам плавления, кристаллизации и другим технологическим свойствам подобны МК, однако в 2-5 раз его дешевле. В связи с этим фальсификация МК в шоколадной продукции путем его полной или частичной замены - частое явление. Подлинность масла какао контролируют методом обращенно-фазовой ВЭЖХ по содержанию триглицеридов (ТГ) в жировой фазе. Целью работы явился анализ данных ВЭЖХ по составу ТГ в натуральном МК различного происхождения и условий репродукции какао-бобов. Установлены генотипические и фенотипические тренды в этом составе. Показано, что выявленные значимые парные корреляции $\mathrm{y}=\mathrm{ax}+\mathrm{b}$ между содержанием ТГ могут быть использованы в проверке подлинности МК. При этом необходимо контролировать содержание и соотношения не только основных ТГ с позиционной специфичностью - ТГ из пальмитиновой, олеиновой и стеариновой кислот (POP, POS и SOS), в которых олеиновая кислота находится в sn-2 позиции, но и ТГ, доля которых составляет 1-5\%. Так, при росте содержания в масле какао РОP симбатно растет POS, асимбатно изменяется содержание OOA, асимбатно доле POS падает содержание OOO, SOL, SOO, PPP, при этом растет содержание SOA. При росте доли SOS падает доля РОO, PSL. Наиболее тесная биохимическая симбатная корреляция в составе МК наблюдалась для соотношения SOS/SOA, коэффициент детерминации R2=0.95. Установленные природные корреляционные взаимосвязи могут быть использованы не только в проверке подлинности масла какао, но и в дальнейших биологических, биохимических и диетологических исследованиях.

Ключевые слова: масло какао, заменители масла какао, триглицериды, обращенно-фазовая ВЭЖХ, природные корреляционные взаимосвязи.

\section{Введение}

Масло какао (МК) является основным сырьевым компонентом шоколада, формирующим его отличительные органолептические свойства. МК состоит на $98 \%$ из триглицеридов (ТГ) и содержит $2 \%$ других гидрофобных липоидных соединений [1-3]. Существует широкая линейка эквивалентов масла какао, заменителей и улучшителей, которые по теплофизическим свойствам - температурам плавления и кристаллизации и некоторым другим технологическим свойствам подобны маслу какао [2-4]. Эти аналоги МК изготавливают из натуральных либо модифицированных растительных масел с добавлением или без добавления животных жиров. Так, эквиваленты МК, обладающие совместимостью с ним в любых соотношениях, имеют сходный с МК состав жирных кислот (ЖК), содержат не более $1 \%$ лауриновой кис- 
лоты, не менее 50\% 2-олеодинасыщенных ТГ, до 2\% транс-изомеров ЖК. Эквиваленты МК получают из натуральных и фракционированных масел тропического происхождения или модифицированных растительных масел. В улучшителях МК SOS-типа основным компонентом является 2-олеодистеарин (до 70\%), они содержат не более $1 \%$ лауриновой кислоты. Изготавливают такие улучшители из натуральных и фракционированных масел тропического происхождения, либо из модифицированных растительных масел. Известны заменители МК РОР-типа, обладающие частичной совместимостью с МК, основным компонентом которых является 2 -олеодипальмитин (>50\%), с массовой долей лауриновой кислоты не более $1 \%$. Они производятся из натуральных и фракционированных масел тропического происхождения или модифицированных растительных масел. Наконец, в качестве заменителей МК применяют нетемперируемые заменители нелауринового типа и лауринового типа (в этих заменителях содержание лауриновой кислоты составляет не менее 40\%). Все упомянутые аналоги МК при прочих схожих теплофизических и технологических свойствах в 2-5 раз дешевле последнего, в связи с чем производители кондитерской продукции (полупродуктов и готовых изделий) активно заменяют МК с целью удешевления и/или фальсификации продукции.

МК является одним из наиболее простых натуральных жиров с преобладанием трех ТГ из пальмитиновой, олеиновой и стеариновой кислот (POP, POS и SOS) и до 20 минорных ТГ [1-5]. На рис. 1 представлен пример содержания ТГ в МК с различным числом атомов углерода в молекуле, по данным [5].

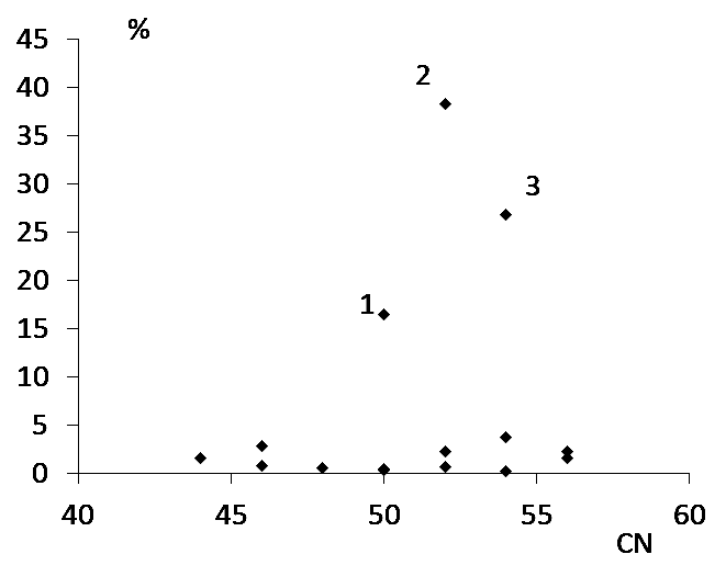

Рис. 1. Распределение ТГ в МК (\%) по числу атомов углерода в молекуле (CN): 1 - POP; 2 - POS; 3 - SOS

B пищевой технологии для масел и жиров принято выделять 4 фракции ТГ: 1я - тринасыщенные ТГ(S,S,S), 2-я - динасыщенные, мононенасыщенные TГ(S,S,U), 3-я - мононасыщенные, диненансыщенные ТГ(S,U,U); 4-я - триненасыщенные $\mathrm{T \Gamma}(\mathrm{U}, \mathrm{U}, \mathrm{U})[6]$. Отличительной особенностью основных ТГ, придающих специфику свойствам МК является их строение. Они являются симметричными мононенасыщенными ТГ (S,U,S), т.е. ТГ во 2-м положении остатка глицерина (sn-2 позиция) находится остаток мононезамещенной кислоты - олеиновой, а пальмитиновая кислота и стеариновая кислота расположены в sn-1 и sn-3 позиции соответственно. Обозначение saturated (S) означает остаток насыщенной, a unsaturated (U) - ненасыщенной ЖК. В этом плане ТГ масла какао можно распределить следующим образом: доля ТГ $(\mathrm{S}, \mathrm{S}, \mathrm{S})$ - 3-6\%, ТГ $(\mathrm{U}, \mathrm{U}, \mathrm{U})$ - до 1\%, ТГ (S,U,U) - 8-15\%, ТГ (S,U,S) - 75-85\%, из этих ТГ в масле какао содержится POP $13-23 \%$, POS - 36-47 \%, и SOS - 22-31\%, 
симметричных ТГ (S,U,S), таких как SOL, POL и SOA может содержаться до 1-2\% и менее $[2,5,7,8]$.

Целью настоящей работы был анализ хроматографических данных о триглицеридном составе масла какао для выявления наиболее характерных природных соотношений ТГ и проверки, насколько выявленные корреляции могут служить идентификации натурального масла какао и обнаружению фальсификатов.

\section{Экспериментальная часть}

Для статистического анализа были использованы результаты исследований $[2,7,8]$. В табл. 1 приведены усредненные данные по составу ТГ в МК, полученного из какао-бобов, произведенных в различных регионах. Парные корреляции определяли в табличном процессоpe Microsoft Excel 2007. Обозначения сложноэфирных фрагментов ЖК в ТГ: Р - пальмитиновая, O - олеиновая, S - стеариновая, L - лауриновая, М - миристиновая и А - арахиновая. Точное расположение остатков ЖК в структуре ТГ указано только для симметричных триглицеридов POP, POS и SOS.

Таблица 1. Триглицеридный состав масла какао в бобах из разных мест репродукции[2]

\begin{tabular}{|c|c|c|c|c|c|c|c|}
\hline ТГ & Самоа & Кот-д’Ивуар & Эквадор & Малайзия & Гана & Нигерия & Бразилия \\
\hline POS & 38.3 & 36.6 & 36.3 & 36.6 & 37.3 & 37.4 & 34.6 \\
\hline SOS & 26.8 & 23.8 & 26.9 & 28.4 & 26.8 & 26.4 & 23.7 \\
\hline POP & 16.4 & 15.9 & 15.3 & 13.8 & 15.2 & 14.8 & 14 \\
\hline SOO,PPP & 3.7 & 6.0 & 4.8 & 3.8 & 4.5 & 5.1 & 8.4 \\
\hline PSL & 2.8 & 3.6 & 2.8 & 2.8 & 3.2 & 3.4 & 3.4 \\
\hline POO & 2.2 & 4.4 & 3.5 & 2.7 & 2.6 & 3.2 & 5.5 \\
\hline SOA & 2.2 & 1.6 & 2.1 & 2.5 & 2.2 & 1.9 & 1.6 \\
\hline PPL & 1.6 & 1.9 & 1.9 & 1.5 & 1.9 & 1.9 & 1.7 \\
\hline OOA & 1.6 & 1.0 & 1.2 & 1.6 & 1.4 & 1.2 & 1.5 \\
\hline POL & 0.8 & 0.6 & 0.7 & 0.6 & 0.6 & 0.8 & 1.1 \\
\hline SSP & 0.7 & 0.8 & 0.9 & 1.0 & 1.3 & 0.4 & 0.2 \\
\hline SOL & 0.5 & 0.9 & 0.8 & 0.7 & 0.4 & 0.8 & 1.0 \\
\hline PPS & 0.4 & 0.4 & 0.3 & 0.6 & 0.0 & 0.7 & 0.3 \\
\hline MOO,MMP & 0.3 & 0.2 & 0.3 & 0.5 & 0.2 & 0.2 & 0.2 \\
\hline OOO & 0.2 & 0.8 & 0.8 & 0.8 & 0.5 & 0.4 & 0.9 \\
\hline
\end{tabular}

\section{Обсуждение результатов}

Жирнокислотный и триглицеридный состав МК, его эквивалентов, заменителей и улучшителей хорошо изучен хроматографическими методами [1,5,7-9]. Для примера приведем на рис. 2 типичную хроматограмму ТГ масла какао, полученную методом обращенно-фазовой ВЭЖХ [5]. В статье [5] обсуждены хроматографические данные различных марок шоколада и шоколадных глазурей, демонстрирующие возможности метода ВЭЖХ в выявлении содержания МК в шоколадной продукции и фальсификатов МК разного происхождения. В жировой фазе 24 образцов шоколада и 9 шоколадной глазури по данным [5] доля МК составляла от 10 до 25\%, если за эталон взять соотношение трех ТГ (POP, POS и SOS), выявленных для образца МК, полученного из какао, выращенного в Кот-д’Ивуар. Однако это не говорит однозначно о фальсификации проверенной шоколадной продукции. Во-первых, в составе этой продукции согласно ГОСТ или ТУ может быть предусмотрено не чистое МК, а 
его смеси с другими специальными жирами. Так, согласно ГОСТ Р 53897-2010 «Глазурь. Общие технические условия», шоколадные глазури должны содержать не менее 12\% МК. Судя по данным [5], некоторые образцы глазури не выдерживают и этого минимума.

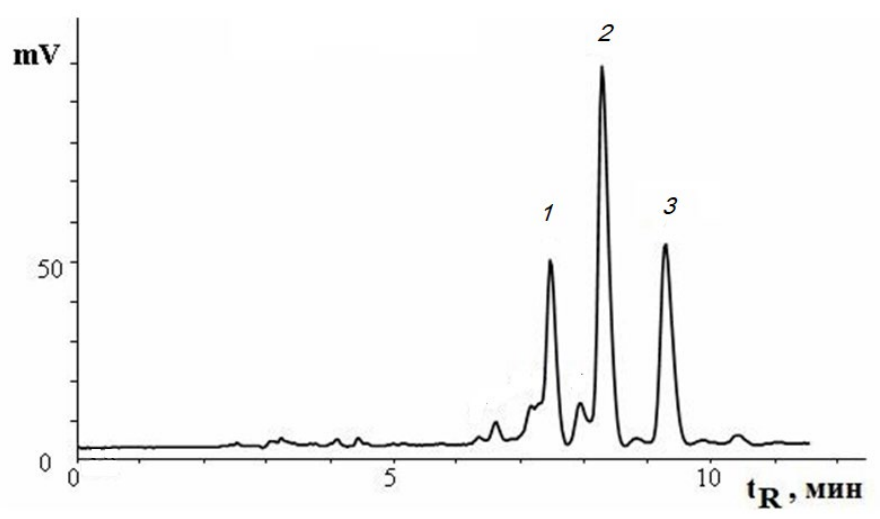

Рис. 2. Разделение триглицеридов масла какао: 1 - POP; 2 - POS; 3 - SOS. Колонка 250×4.6 мм, Kromasil 100-5C18; подвижная фаза - ацетон (расход $1 \mathrm{~cm}^{3} /$ мин); термостат колонок $30^{\circ} \mathrm{C}$; детектор рефрактометрический [5]

Во-вторых, для МК возможно варьирование триглицеридного состава в зависимости от его происхождения - сорта какао-бобов, место репродукции, условий созревания и др. (табл. 1). Так, на сегодняшний день известно 4 сорта какао-бобов: Форастеро (Forastero), Криолло (Criollo), Тринитарио (Trinitario) и Националь (Nacional). Более 90\% мирового производства шоколада получают из бобов сорта Форастеро [1]. Однако известны определенные разновидности одного и того же сорта какао-бобов, произрастающие в разных местностях, в которых соотношение ТГ в МК будет заметно варьировать. Крупнейшие плантации какао-бобов расположены в таких регионах как Кот-д'Ивуар (40\% от мирового экспорта), Гана (20\% от мирового экспорта), Нигерия, Эквадор, Камерун, Байя (Бразилия), Малайзия, Самоа.

Как правило, в публикациях по составу ТГ масла какао и его аналогов обсуждают только вариации трех основных триглицеридов - POP, POS и SOS, и близость к ним составов ТГ в заменителях, содержание лауриновой кислоты и трансизомерных ЖК, по которым вводятся ограничения. По нашему мнению, для повышения надежности идентификации подлинности МК следует обратить внимание на наличие природных корреляций между компонентами жировой фазы натурального МК, которые обусловлены генотипическими и фенотипическими факторами. Гипотеза, из которой исходили авторы статьи, заключается в следующем: состав ТГ в натуральном жире варьирует не статистически случайным образом, а зависит от сорта и условий репродукции сырья, некоторые ТГ симбатно варьируют, другие асимбатно. Данные [2,7-9] позволяют в первом приближении проверить эту гипотезу.

В табл. 2 приведены результаты статистической обработки этих данных. Построение матрицы парных корреляций выявило несколько линейных трендов со значимыми величинами достоверности аппроксимации $\left(R^{2} \geq 0.51\right): y=a x+b(n=9, P=0.95)$, где $x$ - содержание одного ТГ, а $y$ - содержание другого ТГ. Эти корреляции подтверждают наличие генотипического и фенотипического влияния на состав ТГ в МК. Так при росте содержания в масле POP симбатно растет POS, асимбатно изменяется содержание OOA, асимбатно доле POS падает содержание OOO, SOL, SOO, PPP, при этом растет содержание SOA. При росте доли SOS падает доля POO, PSL. Ранее наличие природных корреляций были обнаружены между содержанием ЖК в маслах 
и жирах $[10,11]$, фракционирование, частичная гидрогенизация, смешивание жиров и масел приводит к нарушению естественных соотношений. Выявление этих нарушений является дополнительным признаком фальсификации или неаутентичности продукта. Этот подход по аналогии может быть применен и для интерпретации соотношений ТГ. Так, в работе [8] приведен триглицеридный состав эквивалента МК, в нем соотношение POS/POP явно выбивается из корреляции (1) (табл.2), если в натуральном МК оно составляет около 1.5, то в приведенном эквиваленте МК оно равно 0.5.

Таблица 2. Линейные тренды $y=a x+b$ и коэффициенты детерминации $R^{2}$ для вариаций соотношений ТГ в натуральном масле какао $(n=9, P=0.95)$

\begin{tabular}{|c|cr|c|}
\hline $\mathrm{T}_{1} / \mathrm{T} \Gamma_{2}$ & \multicolumn{2}{|c|}{ Тренд } & Коэффициенты детерминации $R^{2}$ \\
\hline $\mathrm{POS} / \mathrm{POP}$ & $y=0.62 \mathrm{x}-7.73$ & $(1)$ & 0.83 \\
\hline $\mathrm{POP} / \mathrm{OOA}$ & $y=-0.04 x+1.98$ & $(2)$ & 0.77 \\
\hline $\mathrm{POS} / \mathrm{OOO}$ & $y=-0.15 x+6.23$ & $(3)$ & 0.65 \\
\hline $\mathrm{POS} / \mathrm{SOL}$ & $y=-0.14 x+5.9$ & $(4)$ & 0.58 \\
\hline $\mathrm{POS} / \mathrm{POO}$ & $y=-0.65 x+27.4$ & $(5)$ & 0.62 \\
\hline $\mathrm{POS} / \mathrm{SOO}, \mathrm{PPP}$ & $y=-1.17 x+48.3$ & $(6)$ & 0.70 \\
\hline SOS/MOO,MMP & $y=0.05 x-0.93$ & $(7)$ & 0.52 \\
\hline $\mathrm{SOS} / \mathrm{POO}$ & $y=-0.57 x+18.3$ & $(8)$ & 0.72 \\
\hline $\mathrm{SOS} / \mathrm{PSL}$ & $y=-0.16 x+7.27$ & $(9)$ & 0.65 \\
\hline $\mathrm{POL} / \mathrm{SOO}, \mathrm{PPP}$ & $y=6.36 x+0.46$ & $(10)$ & 0.51 \\
\hline $\mathrm{POL} / \mathrm{SSP}$ & $y=-1.75 x+2.06$ & $(11)$ & 0.75 \\
\hline $\mathrm{POO} / \mathrm{SOO}, \mathrm{PPP}$ & $y=1.35 x+0.53$ & $(12)$ & 0.93 \\
\hline SOS/SOO,PPP & $y=-0.81 x+26.4$ & $(13)$ & 0.75 \\
\hline SOS/SOA & $y=0.23 x-4.05$ & $(14)$ & 0.95 \\
\hline POO/SOA & $y=-0.25 x+2.86$ & $(15)$ & 0.72 \\
\hline PSL/SOA & $y=-0.82 x+4.6$ & $(16)$ & 0.71 \\
\hline
\end{tabular}

*Соотношение содержаний ТГ $x / y$

Для средней фракции пальмового масла, часто применяемого для приготовления заменителей МК это соотношение равно 0.2. Обратим внимание на выявленную тесную симбатную корреляцию (14) для пары SOS/SOA. В работе [8] изучен состав ТГ не только образца МК, но и 5 его эквивалентов различного генезиса и пальмового масла. Если для натурального МК соотношение SOS/SOA колеблется в пределах 11-15, за исключением образца МК из Бразилии [9], то для 2 образцов эквивалента МК оно составляет 31 и 39, а для одного образца - 5, и только в двух образцах оно равно 16. Для эквивалента МК в работе [9] величина соотношения SOS/SOA coставляет 54. В средней фракции пальмового масла, как и во всем пальмовом масле SOA вообще не идентифицирован. Таким образом, для проверки подлинности МК наличие характерных соотношений не только основных, но и минорных ТГ может быть весьма информативным.

\section{Заключение}

Анализ данных ВЭЖХ по составу ТГ в натуральном МК различного происхождения обнаружил наличие генотипических и фенотипических трендов в этом составе. Установленные тренды могут быть использованы в проверке подлинности масла какао, в дальнейших биологических, биохимических и диетологических исследованиях. Кроме этого сопоставление природных соотношений ТГ масла какао и соотношений ТГ в эквивалентах масла какао, его заменителях, улучшителях и смесях позволяет с большей надежностью выявлять некондиционную и фальсифицированную 
продукцию. При этом необходимо контролировать содержание и соотношения не только основных триглицеридов с позиционной специфичностью - POP, POS и SOS, но и ТГ, доля которых составляет 1-5\%.

Исследования проведены при финансовой поддержке гранта № $M К-590.2020 .8$

\title{
Список литературы
}

1. Afoakwa E.O. Chocolate science and technology. West Sussex: Wiley-Blackwell. 2010. 296 p. DOI: 10.1002/9781444319880

2. Lipp M., Anklam E. // Food Chemistry. 1998. Vol. 62. pp. 99-108. DOI: 10.1016/S0308-8146(97)00160-X

3. Минифай Б.У. Шоколад, конфеты, карамель и другие кондитерские изделия. СПб. Профессия. 2008. 816 с.

4. Jahurul M.H.A., Zaidul I.S.M., Norulaini N.A.N. et al. // Journal of Food Engineering. 2013. Vol. 117. No 4. pp. 467-476. DOI: 10.1016/j.jfoodeng.2012.09.024

5. Индина И.В., Туртыгин А.В., Дейнека В.И., Дейнека Л.А. // Сорбиионные и хроматографические прочессы. 2013. Т. 13. № 1. C. 23-31.

6. О’Брайен Р. Жиры и масла. Производство, состав и свойство, применение. СПб. Профессия. 2007. 752 с.
7. Линовская Н.В., Мазукабзова Э.В., Кондратьев Н.Б., Крылова Э.Н. // Вестник МГТУ. 2019. Т. 22. № 3. C. 404-412. DOI: 10.21443/1560-9278-2019-22-3-404-412

8. Павлова И.В., Коблицкая М.Б. // Becmник ВНИИЖ. 2017. № 1-2. С. 7-11.

9. Souza C.D. Block J. M. // Journal of Food Science and Technology-Mysore. 2018. Vol. 55. No 2. pp. 767-775. DOI: 10.1007/s13197-017-2989-6

10. Рудаков О.Б., Рудакова Л.В., Букша М.С. // Сорбиионные и хроматографические nроuессы. 2019. T. 19. № 1. C. 8-22. DOI: 10.17308/sorpchrom.2019.19/643

11. Рудаков О.Б., Полянский К.К. // Переработка молока. 2018. № 4. С. 50-51.

12. Пороховинова Е.А., Шеленга Т.В., Косых Л.А. и др. // Экологическая генетика. 2016. T. 14. № 1. C. 13-26. DOI: 10.17816/ecogen14113-26

\section{Identification of adulterated cocoa butter by using HPLC to evaluate the composition of triglyceride}

\author{
C2020 Rudakov O.B. ${ }^{1}$, Rudakova L.V. ${ }^{2}$, Saranov I.A. ${ }^{3}$, \\ Buksha M.S. ${ }^{2}$, Rudakov Ya.O. ${ }^{1}$ \\ ${ }^{1}$ Voronezh State Technical University, Voronezh \\ ${ }^{2}$ Voronezh State Medical University named after N.N. Burdenko, Voronez ${ }^{h}$ \\ ${ }^{3}$ Voronezh State University of Engineering Technologies, Voronezh
}

\begin{abstract}
Cocoa butter (CB) is an expensive raw material used to make chocolate. This component determines the specific organoleptic properties of chocolate products. There is also a large variety of cocoa butter equivalents (substitutes and improvers) which, while having similar technological properties (namely, thermal and physical properties, such as the melting point, crystallisation temperature, etc.), are 2-5 times cheaper than cocoa butter. Therefore, confectionery manufacturers often use various substitutes together with or instead of cocoa butter. Adulterated cocoa butter can be identified by using reverse-phase HPLC to evaluate the ratio of triglycerides (TG) in fat. The purpose of our study was to analyse the results of HPLC of TG in pure CB of various origin and conditions of cocoa beans production. The genotypic and phenotypic trends in the composition of triglycerides were determined. The study demonstrated that the obtained relevant pairwise correlations $y=a x+b$ between the ratio of TG of various types can be used to identify adulterated cocoa butter. It is important to monitor the content and correlation of the basic position-specific TGs, i.e. TGs containing palmitic acid, oleic acid, and stearic acid (POP, POS, and SOS) where the oleic acid is in the sn-2 position, as well as the TGs whose ratio is $1-5 \%$. Thus, when the ratio of POP in the cocoa butter increases, we observe a symbatic growth in the ratio of POS and asymbatic alteration in the content of OOA. The content of OOO, SOL, SOO, and PPP reduces asymbatically to the ratio of POS, while the ratio of SOA grows. When the ratio
\end{abstract}


of SOS increases, the ratios of POO and PSL decrease. The strongest biochemical symbatic correlation was observed for SOS/SOA, with the coefficient of determination being $\mathrm{R}^{2}=0.95$. The determined natural correlations can be applied to identify adulterated cocoa butter. They can also be used in further biological, biochemical, and nutritional studies.

Keywords: cocoa butter, cocoa butter substitutes, triglyceride, reverse-phase HPLC, natural correlations.

\section{References}

1. Afoakwa E.O. Chocolate science and technology. West Sussex: Wiley-Blackwell, 2010, 296 p. DOI: $10.1002 / 9781444319880$

2. Lipp M., Anklam E. // Food Chemistry. 1998, Vol. 62, pp. 99-108. DOI: 10.1016/S0308-8146(97)00160-X

3. Minifai B. U. Shokolad, konfety, karamel' i drugie konditerskie izdeliya. SPb., Professiya, 2008, 816 p.

4. Jahurul M.H.A., Zaidul I. S.M., Norulaini N.A.N. et al., Journal of Food Engineering. 2013, Vol. 117, No 4, pp. 467-476. DOI: 10.1016/j.jfoodeng.2012.09.024

5. Indina I.V., Turtygin A.V., Deineka V.I., Deineka L.A., Sorbtsionnye i khromatograficheskie protsessy. 2013 Vol. 13, No 1, pp. 23-31.

6. O'Braien R. Zhiry i masla. Proizvodstvo, sostav i svoistvo, primenenie, $\mathrm{SPb}$, Professiya, 2007, $752 \mathrm{p}$.

Рудаков Олег Борисович - д.Х.н., зав. кафедрой химии и химической технологии материалов Воронежского государственного технического университета, Воронеж

Рудакова Людмила Васильевна - д.Х.н., зав. кафедрой фармацевтической химии и фармацевтической технологии Воронежского государственного медицинского университета, Воронеж

Саранов Игорь Александрович - к.т.н., инженер патентно-лицензионного отдела, Воронежский государственный университет инженерных технологий. Воронеж

Букша Максим Сергеевич - студент Воронежского государственного медицинского университета, Воронеж

Рудаков Ярослав Олегович - студент Воронежского государственного технического университета, Воронеж
7. Linovskaya N.V., Mazukabzova E.V., Kondrat'ev N.B., Krylova E.N., Vestnik $M G T U$, 2019, Vol. 22, No 3, pp. 404-412. DOI: 10.21443/1560-9278-2019-22-3-404-412

8. Pavlova I.V., Koblitskaya M.B., Vestnik VNIIZh, 2017, No 1-2, pp. 7-11.

9. Souza C.D. Block J.M., Journal of Food Science and Technology-Mysore, 2018, Vol. 55, No 2, pp. 767-775. DOI: 10.1007/s13197-0172989-6

10. Rudakov O.B., Rudakova L.V., Buksha M.S., Sorbtsionnye $i$ khromatograficheskie protsessy, 2019, Vol. 19, No 1, pp. 8-22. DOI: 10.17308/sorpchrom.2019.19/643

11. Rudakov O.B., Polyanskii K.K., Pererabotka moloka, 2018, No 4, pp. 50-51.

12. Porohovinova E.A., Shelenga T.V., Kosyh L.A. et al., Jekologicheskaja genetika, 2016, Vol. 14, No 1, pp. 13-26. DOI: 10.17816/ecogen14113-26

Rudakov Oleg B. - Dr. Sci (Chemistry), head of Department of chemistry and chemical technology of materials of Voronezh state technical University, Voronezh, e-mail: robi57@mail.ru

Rudakova Lyudmila V. - Dr. Sci (Chemistry), head of Department of pharmaceutical chemistry and pharmaceutical technology of Voronezh state medical University, Voronezh. E-mail: vodoley65@mail.ru

Saranov- Igor A. - Ph. D., engineer of the patent and licensing Department, Voronezh state University of engineering technologies. Voronezh. e-mail: mr.saranov@mail.ru

Buksha Maksim S. - Student of Voronezh state medical University, Voronezh. E-mail: snbuk@bk.ru

Rudakov Yaroslav O. - student of Voronezh state technical University, Voronezh. 